\title{
Dust episodes in Hong Kong (South China) and their relationship with the Sharav and Mongolian cyclones and jet streams
}

\author{
Y. C. Lee • Mark Wenig • Zhenxi Zhang • \\ Nobuo Sugimoto • Dave Larko • Thomas Diehl
}

Received: 7 October 2010 / Accepted: 20 January 2011 /Published online: 3 March 2011

(C) Springer Science+Business Media B.V. 2011

\begin{abstract}
The study presented in this paper analyses two dust episodes in Hong Kong, one occurring in March 2006 and the other on 22 March 2010. The latter is the worst dust episode on Hong Kong record. The focus is on the relationship between the dust episodes and the Sharav/Mongolian cyclones and jet streams. The 16 March 2006 episode is traceable to a continental-scale Saharan dust outbreak of 5-9 March 2006 caused by the cold front of an East Mediterranean Sharav cyclone arriving at north-west Africa on 5 March 2006. The eastward movement of the cyclone along the North
\end{abstract}

Y. C. Lee

Guy Carpenter Asia-Pacific Climate Impact Centre,

City University of Hong Kong,

Hong Kong, China

M. Wenig $(\bowtie) \cdot$ Z. Zhang

School of Energy and Environment,

City University of Hong Kong,

Hong Kong, China

e-mail: mark.wenig@cityu.edu.hk

\section{N. Sugimoto}

Atmospheric Remote Sensing Section,

National Institute for Environmental Studies,

Tsukuba,

Ibaraki 305-8506, Japan

D. Larko

Atmospheric Chemistry and Dynamics Branch,

NASA Goddard Space Flight Center,

Greenbelt, MD, USA

T. Diehl

University of Maryland Baltimore County,

Baltimore,

MD, USA
African coast is clearly illustrated in the geopotential height contours. Simulations by the chemistry transport model GOCART provide a visible evidence of the transport as well as an estimate of contributions from the Sahara to the aerosol concentration levels in Hong Kong. The transport simulations suggest that the dust is injected to the polar jet north of the Caspian Sea, while it is transported eastward simultaneously by the more southerly subtropical jet. The major source of dust for Hong Kong is usually the Gobi desert. Despite the effect of remote sources, the 16 March 2006 dust episode was still mainly under the influence of the Mongolian cyclone cold fronts. In the recent episode of 22 March 2010, the influence of the Mongolian cyclone predominated as well. It appears that the concurrent influence of the Sharav and Mongolian cyclones on Hong Kong and East Asia is not a common occurrence. Besides transporting dusts from non-East Asian sources to Hong Kong and East Asia, the strong subtropical jet on 21 March 2010 (i.e. 1 day prior to the major dust episode) is believed to have strengthened an easterly monsoon surge to South China causing the transport of voluminous dusts to Taiwan and Hong Kong the following day.

Keywords Hong Kong dust episode · Sahara dust outbreak $\cdot$ Sharav/Mongolian cyclones · Jet streams

\section{Introduction}

Impact of East Asian and non-East Asian deserts on Hong Kong and Southeast and North Asia

The impact of the East Asian deserts (Gobi and Taklamakan) on Asia is very well documented whereas the literature on the 
impact of non-East Asian dust sources on East Asia is quite limited. However, Saharan dust has been reported to be carried eastward to Korea and Japan (Park et al. 2005; Tanaka et al. 2005; Lee et al. 2006). Lee et al. (2010) have shown that remote non-East Asian sources affect Hong Kong as well, in as much as $96 \%$ of the dust events analysed for the period of 1996 to 2007, and were the sole dust sources on eight dusty days during this period. The most prevalent nonEast Asian influence on Hong Kong was found to be the Thar, the Sahara and the Arabian deserts.

Following up on an earlier investigation (Lee et al. 2010), the current study focuses on the effect of meteorological factors on the two dust episodes that occurred in Hong Kong during the 2006-2010 period. They are found to be associated with one or both of the cyclone systems in spring in the eastern Mediterranean and Mongolia whereas the subtropical and polar jet streams clearly have a role to play especially as transport systems.

Mid-latitude cyclone systems in spring

The transport of Saharan dust to the East Mediterranean occurs predominantly in spring (Kubilay et al. 2000) as a result of mid-latitude cyclones (or cold depressions) which are particularly active in the Mediterranean in this season. These Sharav cyclones or spring depressions, large travelling systems with low-pressure centres, are the most frequent type of Mediterranean cyclones. Occasionally, they may lead to large-scale dust outbreaks in the Sahara desert (Bou Karam et al. 2009). This usually begins with a deep north-south-oriented upper level trough emanating from the Icelandic Low, transporting cold air from high latitudes into North Africa (Meloni et al. 2008). In spring, the temperature difference between the North African continent and the Mediterranean Sea is largest due to the temperature increase over the continent relative to the cold Mediterranean Sea (Bou Karam, et al. 2009). As a result, a cyclone develops in north-west Africa along the front between the cold northern air and the warm African air. After formation, it moves eastward, together with the upper air troughs, along the thermal gradient just south of the North African coast (Moulin et al. 1998) at a speed typically faster than $10 \mathrm{~ms}^{-1}$ (Alpert and Ziv 1989).

Dust transport towards the eastern Mediterranean and the Middle East in spring has long been documented (Ganor, 1994; Kubilay et al. 2000; Engelstaedter et al. 2006). Tanaka et al. (2005) has reported on a strong cyclone in the eastern Mediterranean Sea on 19 March 2003 resulting in a severe dust storm over the Sahara and the Arabian Peninsula and suggested that transcontinental dust transport has occurred.

As for the Asian mid-latitude cyclone, a trough is usually detected near Lake Baikal, which is close to the
Mongolian border. A cyclone forms in Mongolia under the influence of cold continental air. Being downstream of the fronts of the cyclones, the Gobi and maybe also the Taklamakan deserts are often swept by strong cyclonic winds, with vast quantities of dust uplifted.

\section{Cyclones and jet streams}

Cyclone activity has been found to correlate strongly with the subtropical jet (Alpert and Ganor 1993) and, in severe weather events, possibly with an intrusion of a strong polar jet into North Africa (Alpert and Ziv 1989). Alpert and Ziv (1989) believe the jet stream has a major role in producing a complex cyclonic circulation. Prezerakos et al. (2006) has found that the cyclogenesis over the eastern Mediterranean is associated with a juxtaposition of a polar jet streak to the subtropical jet causing cross vertical circulations. Taghavi and Asadi (2007) suggest that major dust and/or sand storms can be produced over the Middle East when the subtropical jet stream moves up from the south and a polar jet moves down from Europe.

A strong waveguide is believed to exist in the Mediterranean-Sahara region and influence the East Asian winter climate through the Rossby wave guide effect of the subtropical jet stream (Watanabe 2004; Hong et al. 2009) and wave activity forced in the Mediterranean-Sahara region could propagate to East Asia. This waveguide is oriented almost zonally and coincides with the subtropical jet (Hsu and Lin 1992) while Chang (1999) suggests that in winter, the primary waveguide follows the subtropical jet over southern Asia into the Pacific.

The East Asian winter monsoon is known to be strengthened by a strong subtropical jet (also known as the East Asian jet) in Asia which is linked to an intensification of the weather and climate systems in Asia and over the Pacific (Yang et al. 2002) involving cyclogenesis, frontogenesis, blocking, storm track activity and the development of other atmospheric disturbances (Yang et al. 2002). When the subtropical jet strengthens, it is accompanied by an adjustment of the large-scale circulation system over Asia and the Pacific. This increases the north-south pressure gradient in the Asia-Pacific region, thereby favouring a southeastward intrusion of the cold air from Siberia. The East Asian winter monsoon (Yang et al. 2002) is intensified as a result.

\section{Data and analysis}

Backward trajectories

The HYSPLIT (HYbrid Single-Particle Lagrangian Integrated Trajectory) model (version 4.9) of the US National 
Oceanic and Atmospheric Administration (NOAA) is used to identify origin of air masses to Hong Kong and other destinations in Asia. Air parcel backward trajectories to Hong Kong and other cities at 00 UTC are computed at $0.5 \mathrm{~km}$ intervals for altitudes up to $6.5 \mathrm{~km}$. The National Centres for Environmental Prediction (NCEP) reanalysis data are used as model input (Draxler and Rolph 2003; Draxler and Hess 2004).

\section{Satellite images}

The distribution of aerosols is observed in NASA's daily aerosol index images from the Ozone Monitoring Instrument (OMI) which represent the aerosol particles. It is possible to observe the phenomena of desert dust transport from this data set. The OMI aerosol index images for the 16 March 2006 episode are compared with simulations of column integrated aerosol optical depth by the GOCART (The Goddard Chemistry Aerosol Radiation and Transport) model (Chin et al. 2002; Ginoux et al. 2004) for the episode as well as pre-episode days.

\section{Transport model simulations}

The GOCART model is driven by assimilated meteorological field from the Goddard Earth Observing System Data Assimilation System version 4 generated by the Goddard Global Modelling and Assimilation Office. The major tropospheric aerosol components, including sulphate, dust, black carbon, organic carbon and sea-salt aerosols can be simulated. Dust particles ranging from 0.1 to $10 \mu \mathrm{m}$ in radius are considered in the model with eight size groups $(0.1-0.18$, $0.18-0.3,0.3-0.6,0.6-1,1-1.8,1.8-3,3-6$ and $6-10 \mu \mathrm{m})$. We use a horizontal resolution of $2^{\circ}$ latitude by $2.5^{\circ}$ longitude and 30 vertical hybrid sigma-pressure layers. The model contains several modules for the aerosol simulation. The emission module includes dust, sulphate and its precursors DMS and $\mathrm{SO}_{2}$, black carbon, organic carbon and sea-salt emissions, while the chemistry module includes in-air and in-cloud oxidations of sulphate precursors. Advection is computed by a flux-form semi-Lagrangian method and boundary layer turbulent mixing uses a second-order closure scheme. Moist convection is calculated using archived cloud mass flux fields. Dry deposition is implemented via surface eddies and gravitational settling. Wet deposition accounts for the scavenging of soluble species in convective updrafts and large-scale and anvil precipitation. Hygroscopic growth of aerosol particles is also included.

\section{Lidar observations}

The lidar data used in this study are from an automated two-wavelength $(1,064 \mathrm{~nm}, 532 \mathrm{~nm})$ polarization lidar
(Sugimoto et al. 2008) at Tsukuba, Japan (36.05 N, 140.12 E, $30 \mathrm{mASL}$ ) providing vertical profiles of the backscattering intensity and depolarization ratio of aerosol particles. Relatively large, nonspherical desert dust particles can be identified by their strong depolarization.

The second lidar data set we used contains aerosol and cloud data from the Cloud-Aerosol Lidar with Orthogonal Polarization onboard the Cloud-Aerosol Lidar and Infrared Pathfinder Satellite Observations satellite (CALIPSO). Since they are available from June 2006 only, no analysis can be performed for the episode of March 2006. The CALIPSO lidar measures both vertical and horizontal distribution of cloud and aerosol layers. Data output for CloudSat (a NASA Earth observation satellite using radar to measure the altitude and properties of clouds) can be generated as a "Curtain plot" which is a two-dimensional representation of data parameter values. They are plotted against altitude or pressure (in the vertical dimension) and distance along the satellite ground track (in the horizontal dimension). In the Vertical Feature Mask plots, a colour bar indicates seven feature types including aerosols and clouds.

Meteorological analysis

Daily composites (mean) of different variables including geopotential height and zonal wind as used in this study (at specified pressure levels) are plotted using NOAA's Physical Sciences Division Earth System Research Laboratory's Interactive Plotting and Analysis facility. NCEP/ NCAR reanalysis data are used.

\section{The two dust episodes occurring in Hong Kong during 2006-2010}

The Asian dust storm affecting Hong Kong on 16 March 2006 started in Mongolia on March 9. It reached the Beijing region on March 10. The dust cloud remained intense as it migrated eastward from China over Korea and Japan, and from there to the Pacific. It remained for days over eastern China. After it arrived in Hong Kong on the 16th, visibility at the hour of maximum $\mathrm{PM}_{10}$ fell to $1.7 \mathrm{~km}$. The maximum hourly $\mathrm{PM}_{10}$ concentration of $323 \mu \mathrm{g} \mathrm{m}^{-3}$ was recorded at the Tai Po station (in the New Territories). Backward trajectories show that the nonEast Asian sources of the Thar, Sahara and Arabian deserts also have a role. However, the GOCART simulations determined the contribution to be only about $2 \%$ from the Sahara and much less from the Arabian and the Thar deserts.

The dust episode occurring on 22 March 2010 represents the worst pollution on record in Hong Kong with the air pollution index (API) exceeding the maximum of the API 
scale (500). While an API exceeding 100 corresponds to an exceedance of the short-term air quality objective (AQO; i.e., 1- and 24-h limits), an API of 201 to 500 means violating both the short-term as well as the long-term AQO values. The episode began as a massive dust storm from the Gobi desert in Mongolia which had been under severe drought. The sandstorm affected 16 provinces including Xinjiang, Inner Mongolia, Shanxi, Shaanxi and Hebei. The dust storm hit Beijing on the 20th, and dust clouds were found in East China. They arrived in Taiwan, Hong Kong, Korea and Japan by 22 March 2010. It was the worst dust storm ever recorded in Korea with $\mathrm{PM}_{10}$ concentration reaching 2,847 $\mu \mathrm{g} \mathrm{m}^{-3}$ (The Korea Herald 2010). A record dust storm condition was also reported in Taiwan with dust levels exceeding 1,000 $\mathrm{\mu g} \mathrm{m}^{-3}$ (Chang and Chang, 2010). Air quality in Hong Kong was reduced to potentially hazardous levels - the $\mathrm{PM}_{10}$ concentration was over $700 \mu \mathrm{g} \mathrm{m}^{-3}$, the highest ever measured, which was more than twice the March 2006 maximum (Fig. 1).
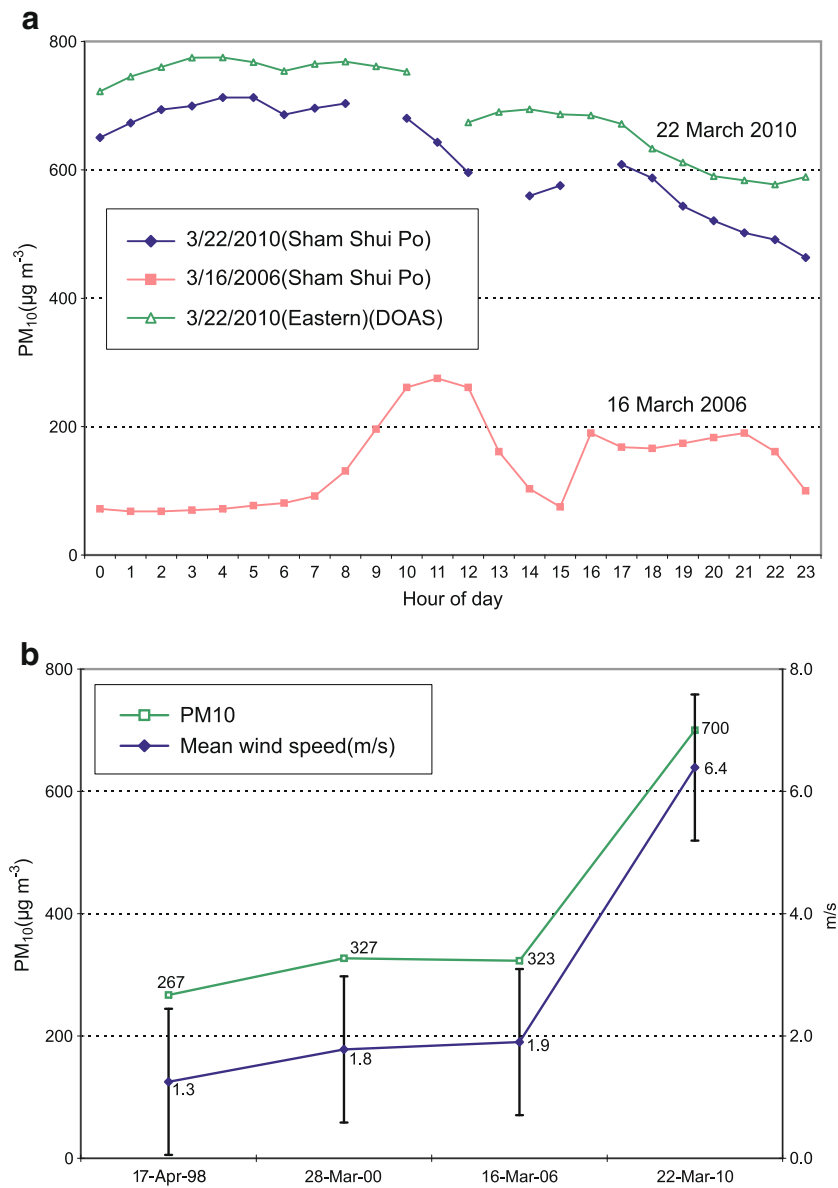

Fig. 1 a $\mathrm{PM}_{10}$ concentrations (hourly) in Hong Kong during dust storm episodes on 16 March 2006 and 22 March 2010. b Maximum $\mathrm{PM}_{10}$ concentrations versus wind speed during dust episodes, Hong Kong 1998-2010 (the vertical bars show the standard error of the mean daily wind speed; correlation coefficient between $\mathrm{PM}_{10}$ and wind speed $=0.999$ )
Dust from mainland desert sources is usually carried southward to Hong Kong by continental high-pressure systems in the monsoon season. It appears likely that the surge of dusts to Hong Kong during the 22 March 2010 episode day is related to the high wind speed of the day owing to an easterly monsoon surge, as suggested by the correlation between $\mathrm{PM}_{10}$ concentration and the daily mean wind speed shown in Fig. 1 for the four dust episodes from 1998 to 2010. The earlier episodes of 1998 and 2000 were reported by Lee and Hill (2003). The mean wind speed for 22 March 2010 was $6.4 \mathrm{~m} / \mathrm{s}$ compared with only $1.9 \mathrm{~m} / \mathrm{s}$ for the 16 March 2006 episode (as reported by the Hong Kong Observatory).

\section{Sharav/Mongolian cyclones and the Hong Kong dust episodes}

The Sharav cyclone and the 2006 dust episode

Backward trajectories to Southeast Asian cities on 16 March 2006 can in fact be tracked to one of the biggest Saharan dust outbreak of 5-9 March 2006, shown in Fig. 2 with the air mass to Hong Kong originating from the Sahara on 6/7 March 2006 (see vertical panel of Fig. 3a). Probably smaller influence is found in Hong Kong in other Saharan dust outbreaks such as the Sahara dust storm of 3-10 March 2004. Sharav cyclones in the Mediterranean have not been associated with Hong Kong before this study.

The continental scale Saharan dust outbreak began on 5 March 2006 over Morocco and Algeria in north-west Africa when the cold front of a cyclone over the Balearic Islands reached North Africa (Kerkmann 2006). The eastward movement of the cyclone along the thermal gradient in the following days is clearly shown in the geopotential height contours at $700 \mathrm{hPa}$ (Fig. 4). The cyclone can be seen moving from western to the eastern Mediterranean in the successive charts as the cold front crossed North Africa from west to east. Around these lows the strong horizontal wind flow and the vertical flow caused uplifting of dusts. The hot air over the Sahara was pulled toward the cooler winter air in the north (Israelevich et al. 2002) transporting it along the Mediterranean coast. The upper air troughs to the west of the surface low is also shown. With the build-up of a highpressure system in the cold air over north-west Africa, strong northerly flow over the central and southern Sahara generated further dust storms in Central Africa.

\section{GOCART model simulation results}

About 10 days after its generation in the Sahara, dust reached Hong Kong on 16 March 2006. Backward trajectories to Hong Kong at 6,000 m in Fig. 3a show that 
(a)

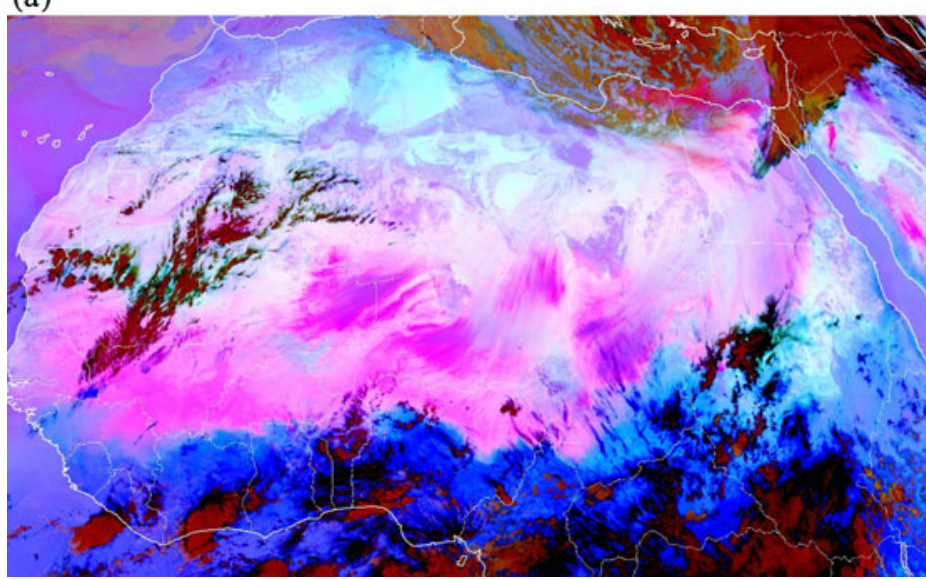

(b)

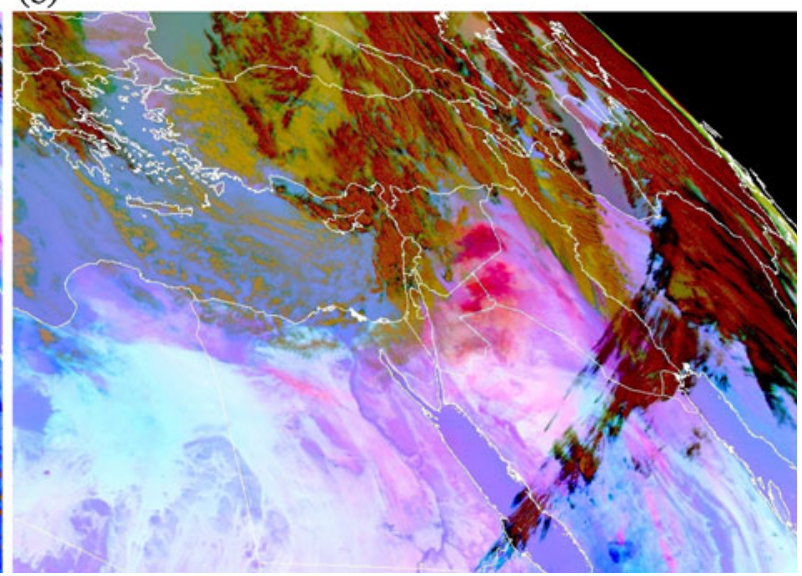

Fig. 2 a Major Saharan dust outbreak shown in full METEOSAT second generation resolution RGB composite, 8 March 2006 (adapted from Jochen Kerkmann (EUMETSAT)). b Dust storm reaches the

the air mass was transported from North Africa via Arabia. The eastward transport and distribution of the Saharan dust from North Africa is visualized in images in Fig. 5 simulated by the GOCART model. The distribution of aerosols from the transport simulations is compared with the OMI daily aerosol index images in Fig. 5. In Fig. 2 the dust is seen to move to the East Mediterranean reaching the Middle East on 9 March. The GOCART images indicate that the dust reached parts of Central Asia north of the Caspian Sea on this day and suggest an injection of dusts to

(a)

NOAA HYSPLIT MODEL

Backward trajectories ending at 0000 UTC 16 Mar 06 CDC1 Meteorological Data

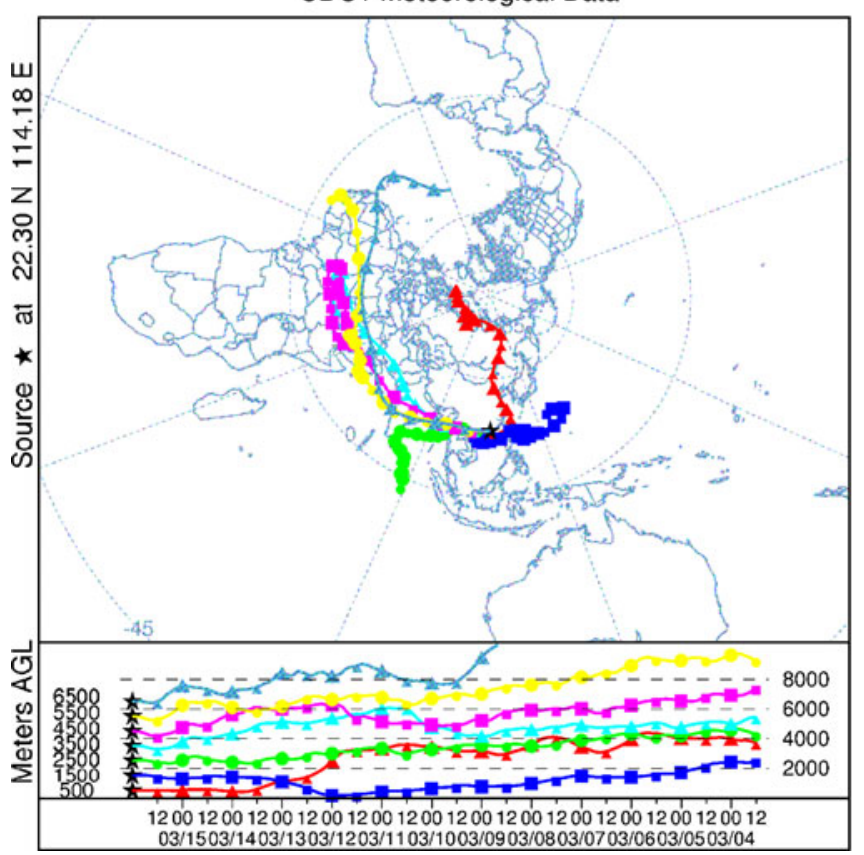

Middle East (9 March 2006; dust appears pink or magenta in RGB composites for easy tracking of dust transport)

the polar jet on 8 March. Dust was simultaneously transported by the more southerly subtropical jet. Both jets appear to carry the Saharan dusts to East Asia.

Saharan dust contribution to Hong Kong is estimated by the GOCART model for the entire month of March 2006, including the episode day of 16 March 2006. Results are shown in Fig. 6 together with the daily mean $\mathrm{PM}_{10}$ concentrations calculated as the mean of all ambient monitoring stations. Obviously Saharan dust contributes more towards the end of the month than mid-March. (b)
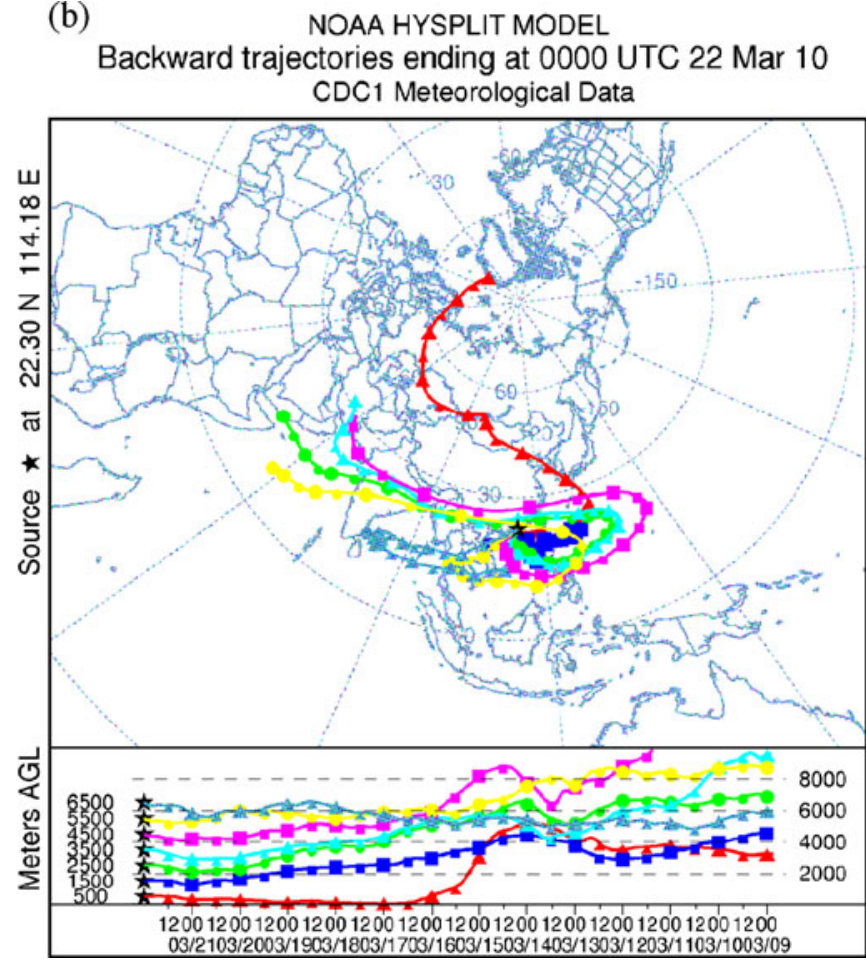

Fig. 3 Back trajectories to Hong Kong from East Asian and non-East Asian dust sources on episode days, Hong Kong a 16 March 2006 , b 22 March 2010 
The Mongolian cyclone

\section{The 16 March 2006 episode}

Compared with the Sharav cyclone, the Mongolian cyclone, in fact, plays a more dominant role in the 16 March 2006 episode. Prior to this episode, dust storms are found in the Gobi desert in Mongolia, where cyclone cold fronts are formed during surges of cold continental air masses. The presence of cyclones in Mongolia is clearly observed in the geopotential height contours in Fig. 7 showing daily mean distribution of cyclone activity. The trough in Mongolia on 8 March was at a geopotential height of $750 \mathrm{gpm}$ (at $925 \mathrm{hPa}$ ). It was a weak easterly monsoon for Hong Kong on 16 March 2006 with local winds subsiding during the day.

\section{(a) 5 March 2006}

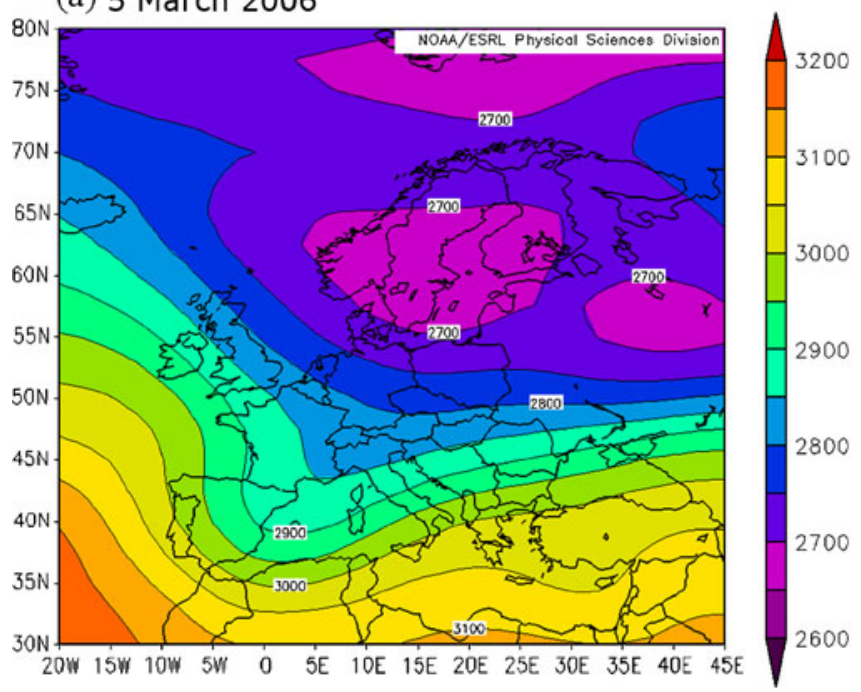

(c) 8 March 2006

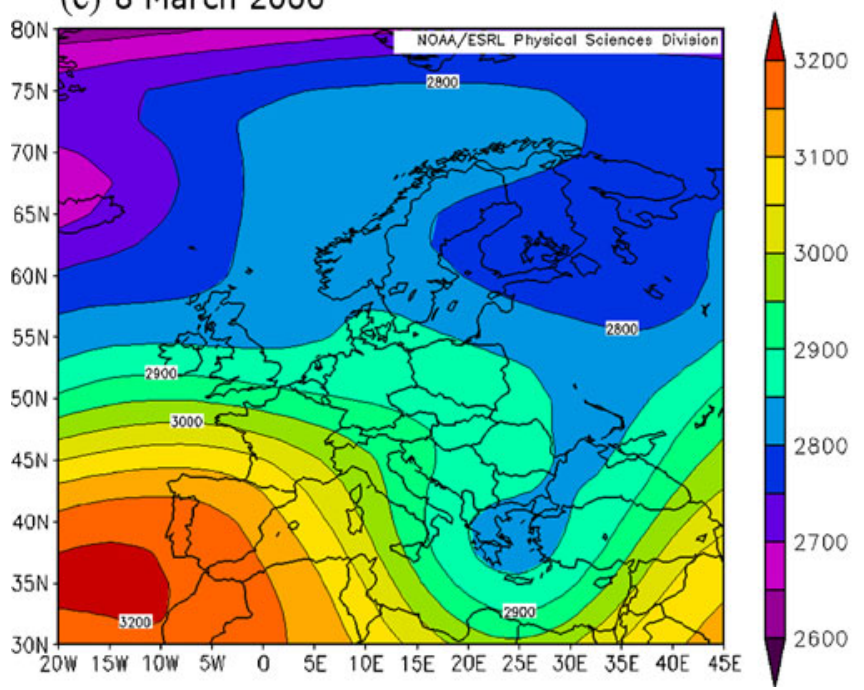

Influence of the non-East Asian dust sources on Southeast Asia often goes as far south as Manila and Hanoi. Backward trajectories on 16 March 2006 (not shown) indicate that winds carried the storm eastward to the cities of Hanoi, Manila, Dongguan (Pearl River Delta of South China), Xiamen (Fujian province), Chongqing (southwest China), Tianjin (North China), Tokyo and Seoul. Lidar observations in Tsukuba, Japan (36.05 N, 140.12 E, $30 \mathrm{mASL}$ ) for mid-March 2006 evidence the dust impact. Figure $8 \mathrm{a}$ and $\mathrm{b}$ show vertical profiles of the backscattering intensity and the depolarization ratio at $532 \mathrm{~nm}$ for the days before and after 16 March 2006. The depolarization ratio plot clearly shows the dust layers on 11-12 March and 15-16 March. It can be seen from the distribution pattern that the main part of the dust layer on (b) 6 March 2006

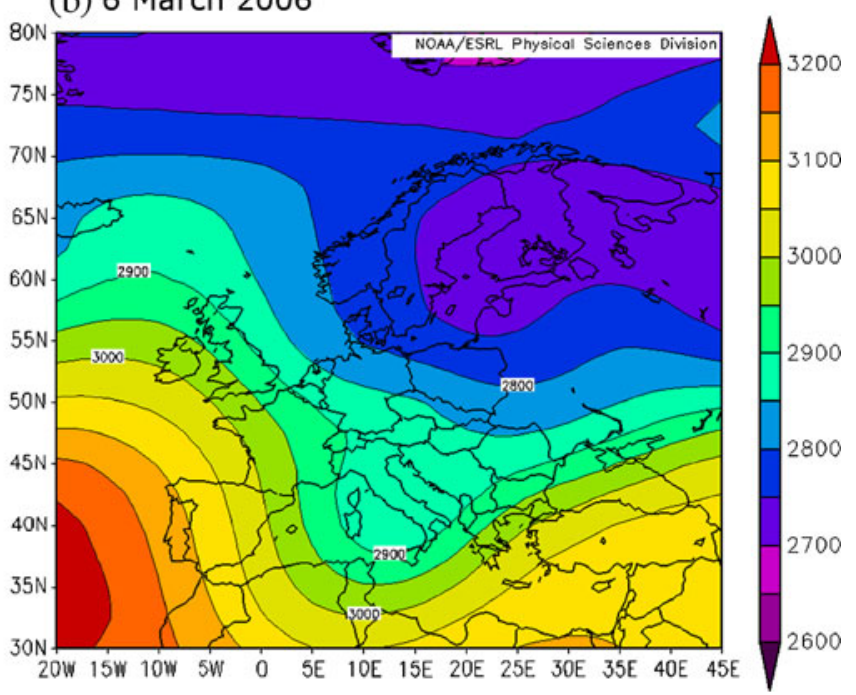

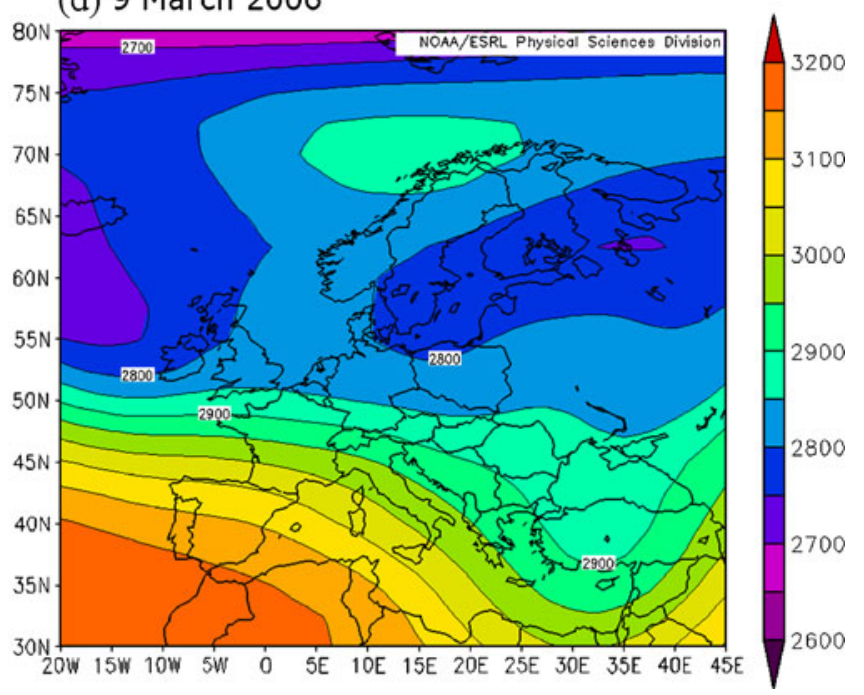

Fig. 4 Mean geopotential height $(700 \mathrm{hPa})$ to show movement of Sharov cyclone from western to eastern Mediterranean during the $5 \mathrm{March}$ 2006 continental dust outbreak in the Sahara 
(a)(i) - (iv)

GOCART AODs due to dust at $550 \mathrm{~nm}$
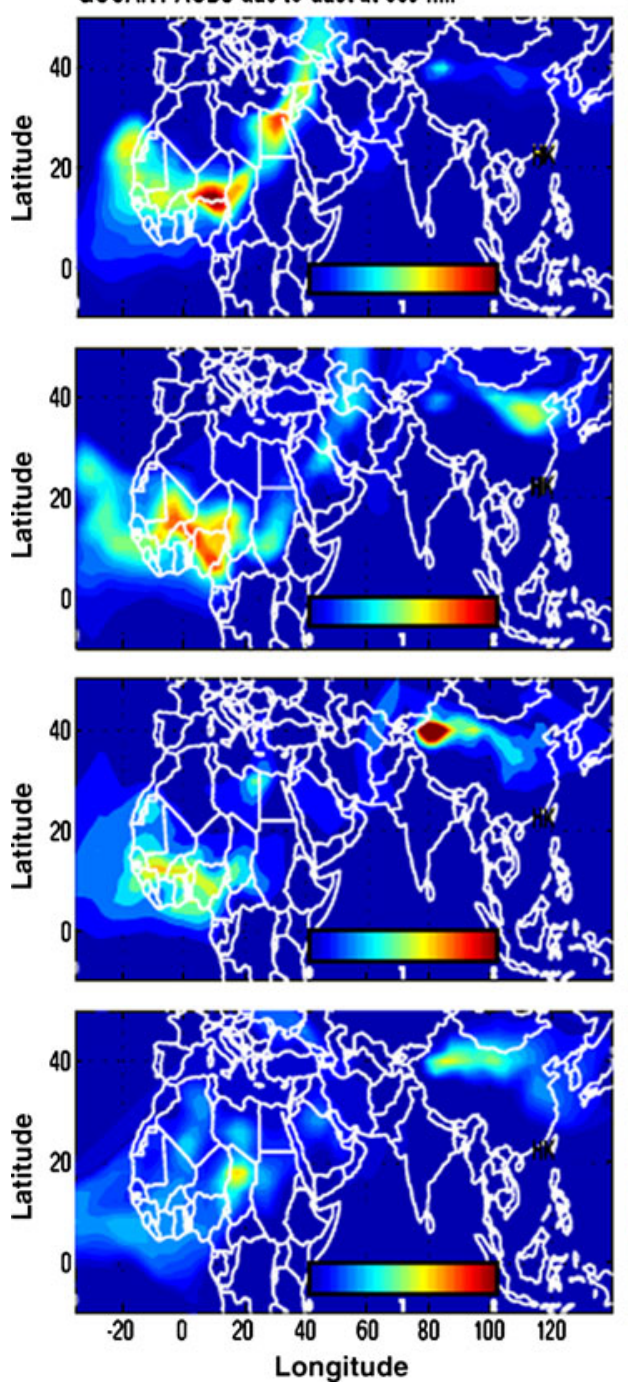

(b)(i)-(iv)

OMl aerosol index
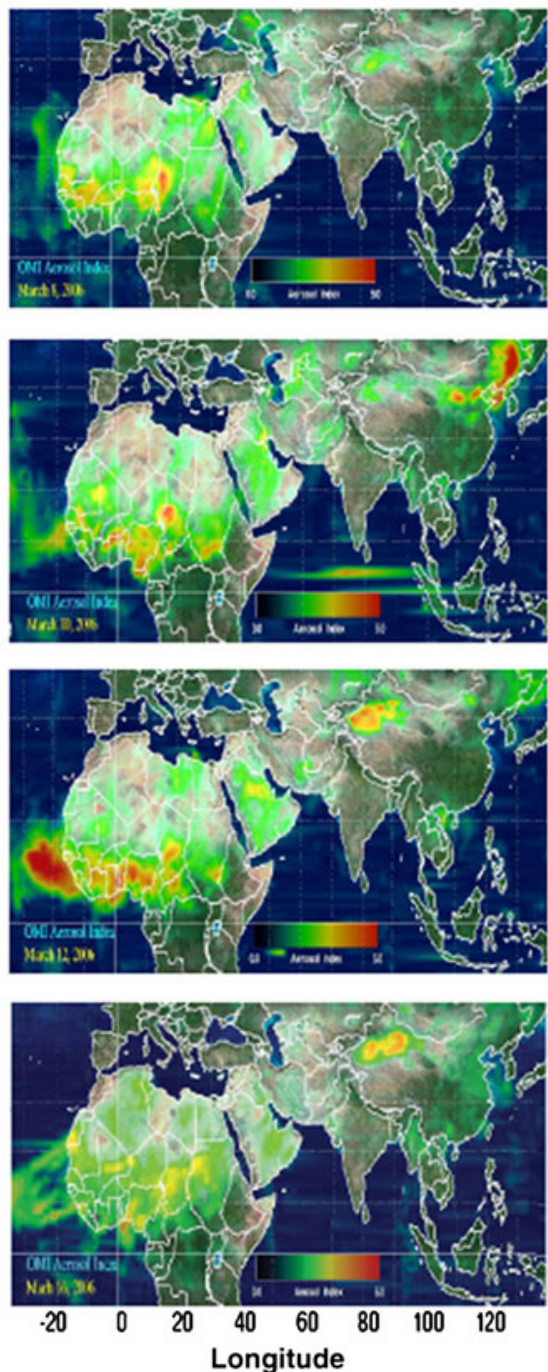

(c)(i)-(iv)

$200 \mathrm{mb}$ Zonal Wind NCEP/NCARReanalysis
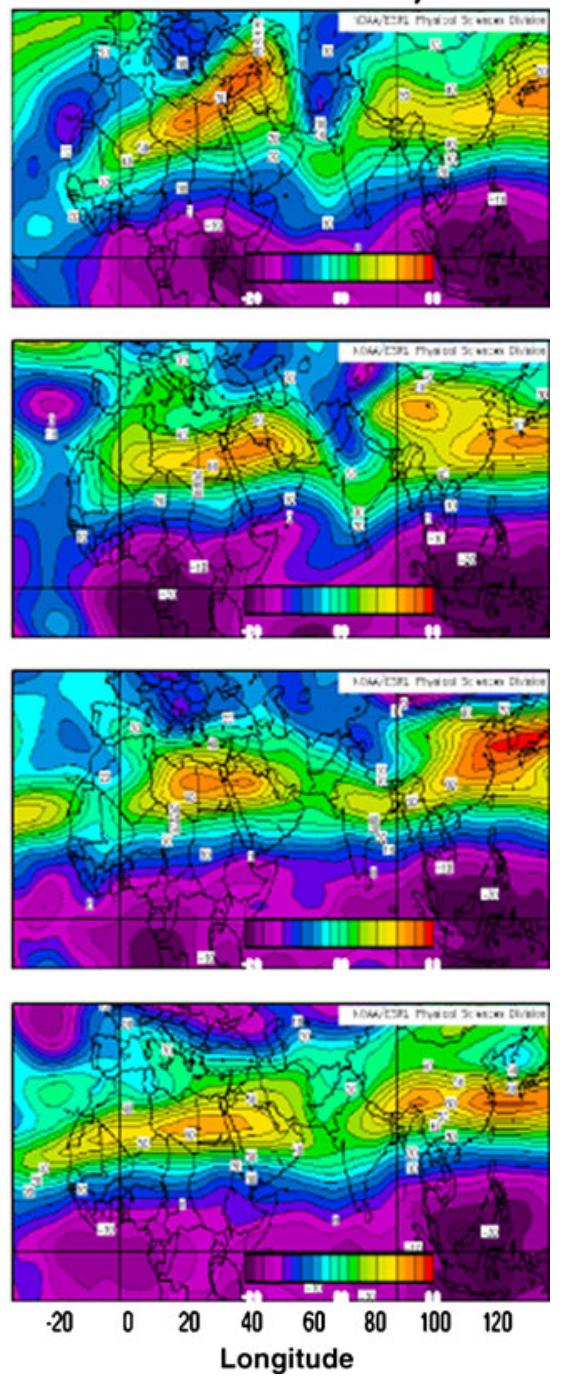

Fig. 5 Mid-March 2006: a GOCART AODs due to dust at $550 \mathrm{~nm}$, b OMI aerosol index and c zonal wind (200 hPa) for (i) 8 March 2006 , (ii) 10 March 2006, (iii)12 March 2006 and (iv)16 March 2006

11-12 March was transported in the lower altitudes up to $3 \mathrm{~km}$ and was taken into the boundary layer on 12 March. The dust layer on 15-16 March was elevated at altitudes of 3$7 \mathrm{~km}$. For Hong Kong, lidar normalized relative backscattering signal at Yuen Long (northwestern Hong Kong) reveals dust layers at 2 to $4 \mathrm{~km}$ on 16 March 2006 (Fig. 8c).

\section{The 22 March 2010 episode}

This episode is primarily due to an intense sandstorm originating from Mongolia. However, some air masses to Hong Kong have originated near the arid fringes of the nonEast Asian Thar and Arabian deserts. Dust layers are shown in the Vertical Feature Mask image from CALIPSO observations at about $3 \mathrm{~km}$ over East China and Hong Kong (at higher levels over southern Japan and the Pacific; Fig. 8d).
Compared to the 2006 episode, the 2010 episode is even more influenced by a cyclone originating from Mongolia as illustrated in Fig. 7b. The geopotential height contours in Fig. $7 \mathrm{~b}$ indicates a trough in Mongolia at $675 \mathrm{gpm}$ (at $925 \mathrm{hPa}$ ) on 18 March 2010, 4 days prior to the episode in Hong Kong. A cold weather front bearing a strong area of low pressure passed at the surface. These mid-latitude cyclones are often associated with large comma-shaped clouds that reveal how air from a wide area gets drawn in toward the lowpressure centre of the storm (NASA Earth Observatory (http:// earthobservatory.nasa.gov/IOTD/view.php?id=43207)).

Dust was carried to the coast of Guangdong on 21 March by a fresh northeast monsoon after a ridge of high pressure was established over eastern China. Hong Kong and Taiwan were both under the same strong easterly monsoon on 21 and 22 March. 
Fig. 6 Saharan dust contribution to Hong Kong as simulated by the GOCART model $\left(\mathrm{PM}_{10}\right.$ concentrations included for comparison) for March 2006

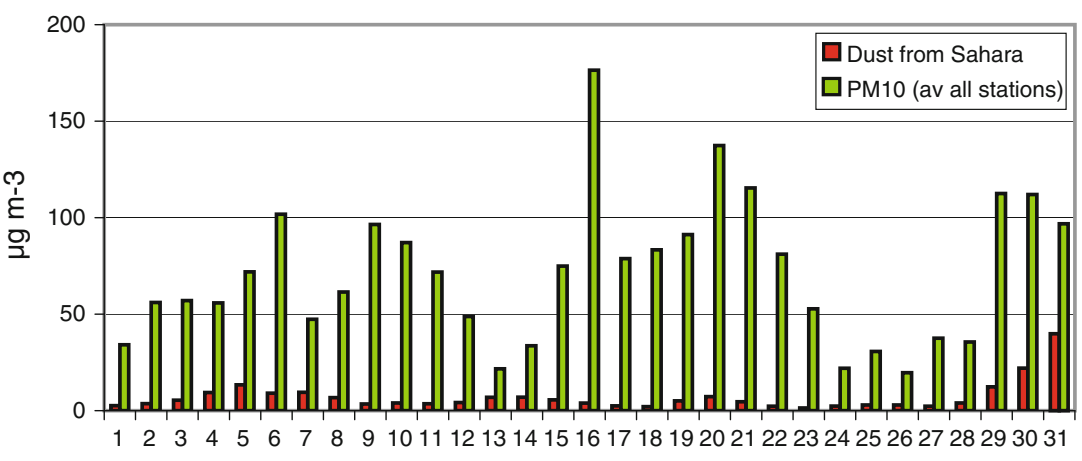

\section{Occurrence of impact of Sharav cyclones on Hong Kong}

Altogether five dust-storm-related pollution episodes have occurred in Hong Kong during the period from 1996 to 2010, on 10 May 1996, 17 April 1998, 28/29 March 2000, 16 March 2006 and 22 March 2010. Only one of these episodes - the episode on 16 March 2006, had air mass origin traceable to a Saharan outbreak and a Sharav cyclone, as reported in this work. This suggests that the simultaneous influence of Sharav cyclone on Hong Kong and East Asia in springtime is not a common occurrence. In an earlier study for the period 1996-2007 (Lee et al. 2010), the Gobi desert emerges as the most frequent origin of dust for Hong Kong. The Mongolian cyclone, therefore, remains to be the overriding influence although, for most of the time, Gobi influences Hong Kong concurrently with nonEast Asian desert sources. It is interesting to note that Saharan dust can contribute as much as $41 \%$, as found on 31 March 2006 from simulations in this study.

\section{Transport pathway by jet streams and its influence on monsoons}

It is clear from the backward trajectories that for the more southern cities of East Asia, including Hong Kong and cities of the Pearl River Delta in South China, non-East Asian dust is transported along a more southerly route via the Asian subtropical jet. By contrast, dusts transported to the more northerly cities such as Tianjin, Tokyo and Seoul are more often carried by the polar jet. The pathway often involves northerly tracks from the eastern Mediterranean region to the Middle East subtropical jet, before entering the polar jet, or occasionally the East Asian subtropical jet. Sometimes the eastern Mediterranean region is bypassed and the route involves more northerly regions.

The Asian subtropical jet is in fact embedded in the mid-latitude westerlies, the strength of which in spring has been suggested (Wang et al. 2005) to contribute to upper tropospheric trans-Pacific transport. The westerlies
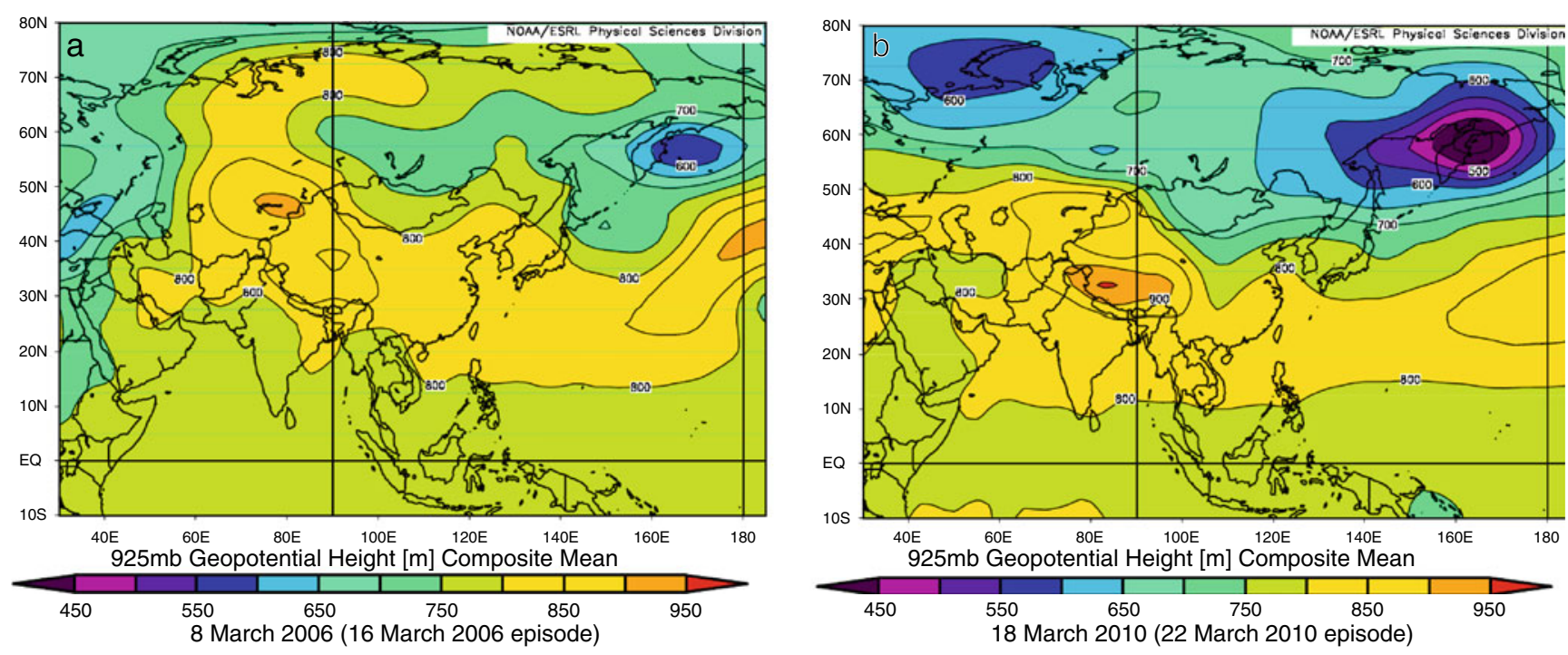

Fig. 7 Mean geopotential height $(925 \mathrm{hPa})$ to show mid-latitude cyclone in Mongolia before dust episode days a 8 March 2006 , b 18 March 2010 

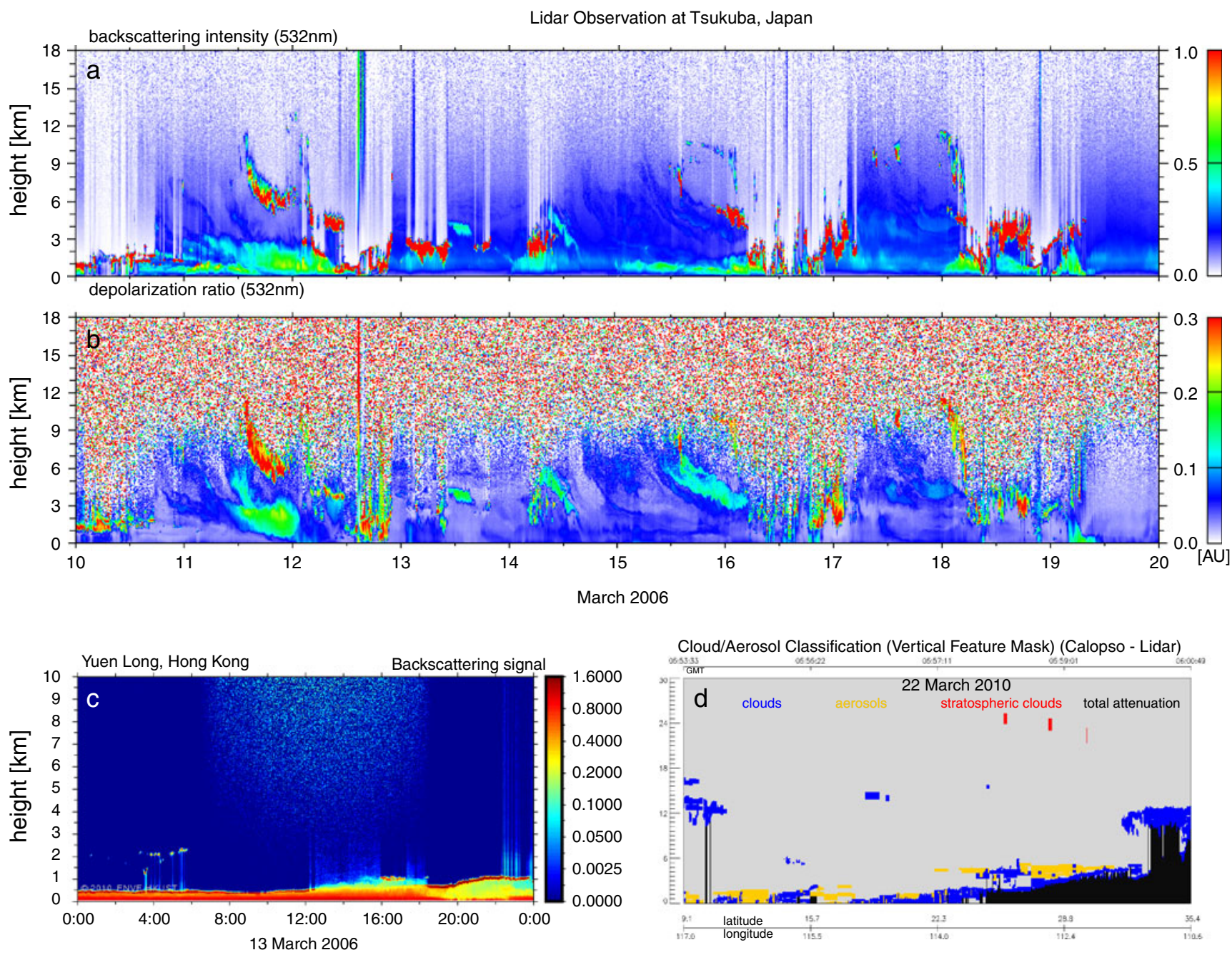

Fig. 8 a, b Lidar observations in Tsukuba, Japan (about $40 \mathrm{~km}$ from Tokyo) around mid-March 2006. c Lidar observation in Yuen Long, Hong Kong (http://envf.ust.hk/dataview/lidar/) d CALIPSO-Lidar

are strongest in winter with speed maxima observed over North Africa and Japan. As revealed in Fig. 5 for the mid-March 2006 episode, the polar jet is generally within the mid-latitudes, roughly between $30^{\circ}$ and $60^{\circ}$, while the subtropical jet stream is generally within the subtropics, and follows a more fixed pattern between approximately $23.5^{\circ}$ and $33^{\circ}$. As evidenced by zonal wind images in Fig. 5, the polar jet splits into two branches - one branch north of the Himalayas and the Tibetan Plateau and the other to their south. The position of the northern jet varies while the southern jet generally flows over northern India and then curves northward over southern China and Japan.

The paths of back trajectories of 6-16 March 2006 from North Africa to East Asia are found to grossly coincide with positions of the polar/subtropical jet streams as observed in the plots of daily composites of zonal wind at $200 \mathrm{hPa}$ in Fig. 5. The daily composite zonal wind plots in
Vertical Feature Mask plot for 22 March 2010 showing dust in Hong Kong and Central China (generated by Giovanni 3 using data from CloudSat)

Fig. 5 show intense jet streams in North Africa and the Middle East on the days from 8 to 16 March prior to or during the 16 March 2006 episode. The jet stream becomes particularly strong in winter and spring. Elliptically shaped isotachs define the jet maximum. The confluence of the subtropical jet with the polar jet in winter and early spring, as seen in Fig. 5, results in a broader and even stronger jet stream, which further speeds up the dust transport. The subtropical and polar jets are best developed in winter and early spring. Both jets migrate further north and higher in altitude during April, with the average wind speeds decreasing. During summer the subtropical jet is only found as random streaks.

The 22 March dust episode was apparently associated with a part of the subtropical jet extending to South China and Hong Kong as shown in Fig. 9. This ridge seems to be steering the easterly monsoon surge drawing voluminous dusts to the area. Consistent with findings of $\mathrm{Wu}$ and Chan 

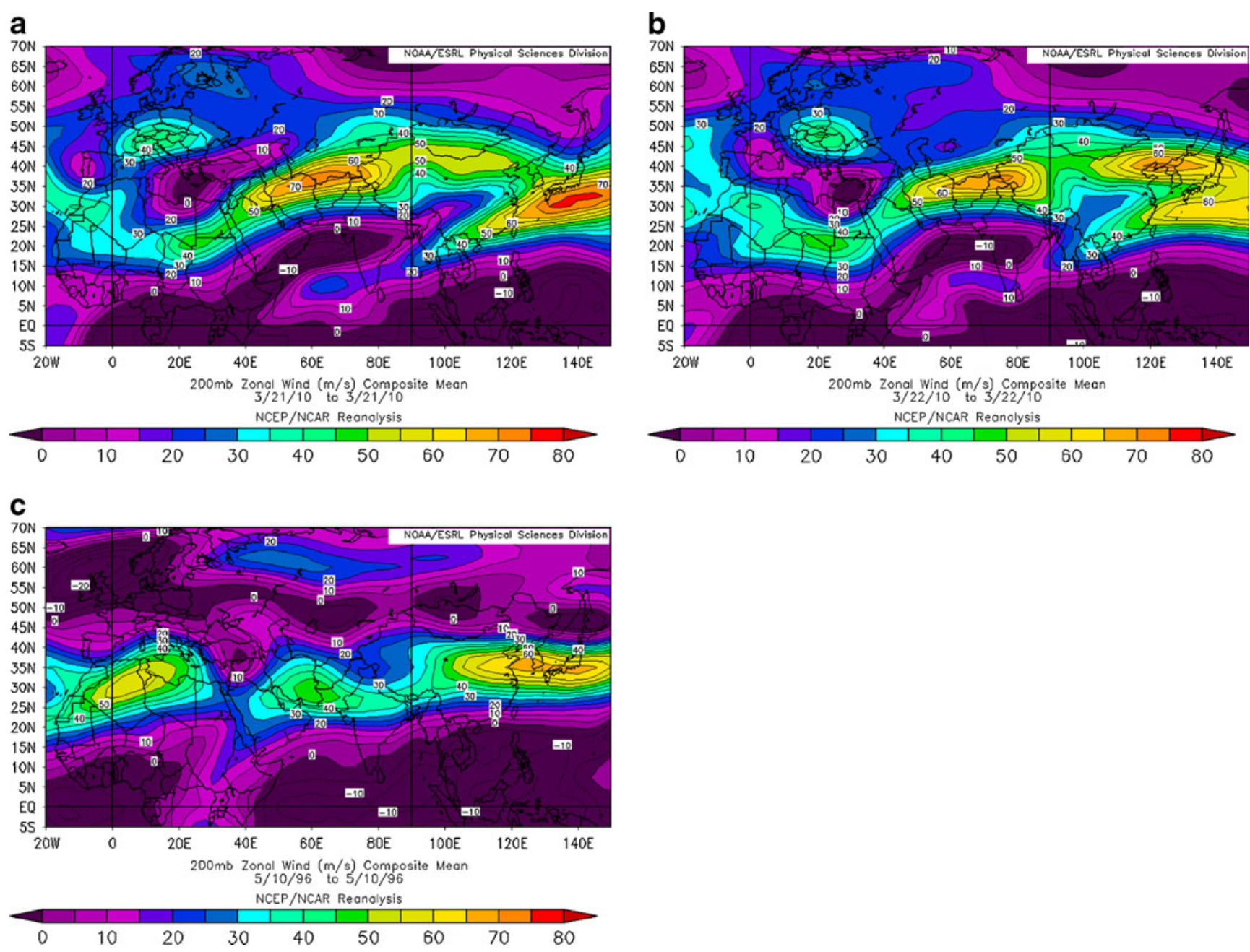

Fig. 9 Zonal wind on a 21 March 2010, b 22 March 2010 (latest episode) and c 10 May 1996 (past episode also affected by easterly monsoon) showing different intensities of the subtropical jet

(1997), the strength of the subtropical jet is found to reach the maximum 1 day before the easterly surge, on 21 March 2010, as shown in Fig. 9, and subsequently weaken on the episode day. By contrast, for the milder dust episode of 10 May 1996, the first reported in Hong Kong and which was also associated with an easterly but weaker monsoon, no extension of the subtropical jet to southeast China is found.

\section{Conclusions}

The two dust episodes occurring in Hong Kong during 2006-2010 are studied with reference to the mid-latitude spring cyclone systems in the eastern Mediterranean and in Mongolia, and the jet streams. While the Mediterranean cyclone system has been found to initiate dust transport to Hong Kong and the Asian cities, the jet stream is found not only to transport dust, but also to strengthen the easterly monsoon and intensify dust transport.
The dust storm affecting Hong Kong on 16 March 2006 moved from North China to affect Korea, Japan and the Pacific. The maximum hourly $\mathrm{PM}_{10}$ concentration for that day in Hong Kong was $323 \mu \mathrm{g} \mathrm{m}^{-3}$. The dust episode occurring on 22 March 2010 was, however, much more severe, not only for Hong Kong, but also for the region. The local air pollution index was raised to record levels in excess of the API scale. The maximum $\mathrm{PM}_{10}$ concentration was over $700 \mu \mathrm{g} \mathrm{m}^{-3}$. This serious episode began as a strong dust storm from the Gobi desert in Mongolia, arriving at Taiwan, Hong Kong, Korea and Japan by 22 March 2010.

Backward trajectories for the 16 March 2006 dust episode reveals that the dust can, in fact, be traced to one of the biggest Saharan dust outbreaks which began on 5 March 2006 in north-west Africa when the cold front of a Mediterranean Sharav cyclone reached North Africa. The crossing of the cold front in North Africa from western to the eastern Mediterranean along the thermal gradient is clearly shown in the geopotential height contours at $700 \mathrm{hPa}$. The air mass to Hong 
Kong originated from the Sahara on 6/7 March 2006 (as shown in the vertical panel of the trajectories) and dust reached Hong Kong on 16 March. The GOCART model simulation of the 6-16 March 2006 period and the corresponding OMI aerosol index images provide visible evidence of dust transport to the East Mediterranean, the Middle East and eventually to the Far East. The GOCART images suggest an injection of dusts to the polar jet in parts of Central Asia north of the Caspian Sea on 8 March, while it was transported simultaneously by the more southerly subtropical jet. The daily composite zonal wind plots show intense jet streams in North Africa and the Middle East on 816 March prior to or during the 16 March 2006 episode. The GOCART model is also used to estimate Saharan dust contribution to Hong Kong for the days in March 2006. Results indicate that contributions were more significant at the end of March rather than mid-March, reaching a high of $41 \%$ on 31 March.

Five dust storm related pollution episodes occurred in Hong Kong during the period of 1996 to 2010, on 10 May 1996, 17 April 1998, 28/29 March 2000, 16 March 2006 and 22 March 2010, respectively. Only one of these-the episode on 16 March 2006, has air mass origin traced to a Saharan outbreak and a Sharav cyclone. This suggests that the influence of Sharav cyclone on Hong Kong and East Asia in the springtime is not a common occurrence despite the frequent impact of the Saharan air masses.

Consistent with an earlier study (Lee et al. 2010), the Mongolian cyclone is the overriding influence in the two dust episodes in 2006 and 2010. During the March 2006 episode, air mass also arrived from the Gobi desert besides the non-East Asian sources. The presence of cyclones in Mongolia are clearly observed in the geopotential height contours. When compared to the 16 March 2006 episode, the March 2010 episode was even more predominantly under the influence of the Mongolian cyclone, as revealed in geopotential height contours showing a trough in Mongolia 4 days before the episode in Hong Kong.

Dusts from mainland desert sources are usually carried southward to Hong Kong by continental high-pressure systems - a weak easterly monsoon in the case of 16 March 2006. A fresh northeast monsoon, however, prevailed on 22 March 2010. Clearly, the strong easterly monsoon contributed to the surge in dust levels (the mean wind speed for the day is $6.4 \mathrm{~m} / \mathrm{s}$ compared with $1.9 \mathrm{~m} / \mathrm{s}$ for the 16 March 2006 episode). Actually, the subtropical jet became very strong 1 day prior to the episode. The easterly monsoon surge was strengthened and brought large volumes of dusts to South China and Hong Kong.

Acknowledgement The work described in this paper was supported by a grant from City University of Hong Kong (project no. 7002458). Thanks are due to the Guy Carpenter Asia-Pacific Climate Impact
Centre of the City University of Hong Kong for research grant support. The provision of air quality data by the Environmental Protection Department of the Hong Kong Special Administrative Region and the advice of Dr Roland Draxler of NOAA are gratefully acknowledged.

\section{References}

Alpert Pinhas, Ganor Eliezer (1993) A jet stream associated heavy dust storm in the Western Mediterranean. J Geophys Res 98 (d4):7339-7349. doi:10.1029/92JD01642

Alpert P, Ziv B (1989) The Sharav cyclone: observations and some theoretical considerations. J Geophys Res 94(15):18,495-18,514

Bou Karam Diana, Flamant Cyrille, Cuesta Juan, Pelon Jacques, Earle Williams (2009) CALIPSO observations on dust emission and transport associated with Saharan cyclones: the February 2007 case (power point presentation)

Chang EKM (1999) Characteristics of wave packets in the upper troposphere. Part II: seasonal and hemispheric variations. J Atmos Sci 56:1729-1747

Chang Shuenn-Chin and Chang Che-Ming (2010) The impact of Asian dust on Taiwan air quality, presentation at the International Symposium on Asian Dust/Aerosol and its Impact on the Global Climate Change August 8-11 2010, Shanghai, China

Chin M, Ginoux P, Kinne S, Holben BN, Duncan BN, Martin RV, Logan JA, Higurashi A, Nakajima T (2002) Tropospheric aerosol optical thickness from the GOCART model and comparisons with satellite and sunphotometer measurements. J Atmos Sci 59:461-483

Draxler RR, Hess GD (2004) Description of the Hysplit_4 modeling system (NOAA Technical Memorandum ERL ARL-224)

Draxler RR, Rolph GD (2003) HYSPLIT (HYbrid Single-Particle Lagrangian Integrated Trajectory) Model access via NOAA ARL READY Website (http://www.arl.noaa.gov/ready/hysplit4.html). NOAA Air Resources Laboratory, Silver Spring, MD

Engelstaedter S, Ina T, Richard W (2006) North African dust emissions and transport. Earth Sci Rev 79:73-100. doi:10.1016/ j.earscirev.2006.06.004

Ganor E (1994) The frequency of Saharan dust episodes over Tel Aviv, Israel. Atmos Environ 28(17):2867-2871

Ginoux P, Prospero JM, Torres O, Chin M (2004) Long-term simulation of global dust distribution with the GOCART model: correlation with North Atlantic Oscillation Environmental Modelling \& Software 19:113-128

Hong CC, Hsu HH, Chia, HH (2009) A study of East Asian cold surges during the 2004/05 winter: impact of East Asian jet stream and subtropical upper-level Rossby wave trains. Terr Atmos Oceanic Sci 20(2):333-343. doi:10.3319/TAO.2008.02.04.01(A)

Hong Kong Observatory http://www.hko.gov.hk/

Hsu HH, Lin SH (1992) Global teleconnections in the 250-mb streamfunction field during the northern hemisphere winter. Mon Weather Rev 120:1169-1190

Israelevich PL, Levin Z, Joseph JH, Ganor E (2002) Desert aerosol transport in the Mediterranean region as inferred from the TOMS aerosol index. J Geophys Res 107(D21):4572. doi:10.1029/ 2001JD002011

Kerkmann Jochen (EUMETSAT) Continental-scale Sahara dust outbreak (5-9 March 2006). http://oiswww.eumetsat.org/ WEBOPS/iotm/iotm/20060308_dust/20060308_dust.html

Kubilay N, Slobodan N, Cyril M, Francois D (2000) An illustration of the transport and deposition of mineral dust onto the eastern Mediterranean. Atmos Environ 34(8):1293-1303

Lee HN, Igarashi Y, Chiba M, Aoyama M, Hirose K, Tanaka T (2006) Global model simulations of the transport of Asian and Sahara 
Dust:total deposition of dust mass in Japan. Water Air Soil Pollut 169:137-166

Lee YC, Hills PR (2003) Cool season pollution episodes in Hong Kong, 1996-2002. Atmos Environ 36(12):2927-2939

Lee YC, Yang X, Mark W (2010) Transport of dusts from East Asian and non East Asian sources to Hong Kong during dust storm related events 1996-2007. Atmos Environ 44:3728-3738. doi:10.1016/j.atmosenv.2010.03.034

Meloni D, di Sarra A, Monteleone F, Pace G, Piacentino S, Sferlazzo DM (2008) Seasonal transport patterns of intense Saharan dust events at the Mediterranean island of Lampedusa. Atmos Res 88 (2):134-148

Moulin C, Lambert CE, Dayan U, Masson V, Ramonet M, Bousquet P, Legrand M, Balkanski YJ, Guelle W, Marticorena B, Bergametti G, Dulac F (1998) Satellite climatology of African dust transport in the Mediterranean atmosphere. J Geophys Res 103(D11):13137-13144

Park C-B, Nobuo S, Ichiro M, Atsushi S, Boyan T, Akihide K, Hie LC, Itsushi U, Toshihiko T, Westphal Douglas L (2005) Longrange transport of saharan dust to East Asia observed with Lidars. SOLA 1:121-124

Prezerakos NG, Flocas HA, Brikas D (2006) The role of the interaction between polar and subtropical jet in a case of depression rejuvenation over the Eastern Mediterranean. Meteorol Atmos Phys 92(1-2):39-151. doi:10.1007/s00703-005-0142-y

Sugimoto N, Matsui I, Shimizu A, Nishizawa T (2008) Lidar network for monitoring Asian dust and air pollution aerosols. Proc. Int.
Geoscience and Remote Sensing Symp. (IGARSS) paper 1618. Boston, MA, IEEE, ISBN: 978-1-4244-2808-3

Taghavi F, Asadi A (2007) The Persian Gulf 12th April 2007 dust storm: observation and model analysis. http://www.eumetsat.int/groups/ $\mathrm{cps} /$ documents/document/pdf conf_p_s5 25 taghavi p.pdf

Tanaka TY, Yasunori K, Chiba M, Takatsugu M, Tomohiro N, Akihiro Y, Akihiro U, Nobumitsu T, Nobumitsu T, Kenji K (2005) Possible transcontinental dust transport from North Africa and the Middle East to East Asia. Atmos Environ 39(21). doi:10.1016/j.atmosenv.2005.03.034

The Korea Herald, 21 March 2010

Wang Yuhang, Choi Yunsoo, Zeng Tao, Ridley Brian, Blake Nicola, Blake Donald, Flocke, Frank (2005)Late-spring increase of transPacific pollution transport in the Upper Troposphere. http://acmg. seas.harvard.edu/publications/yhw2005a.pdf

Watanabe M (2004) Asian jet waveguide and a downstream extension of the North Atlantic Oscillation. J Climate 17:4674-4691

Wu MC, Chan JCL (1997) Upper-level features associated with winter monsoon surges over South China. Mon Weather Rev 125:317340

Yang S, Lau KM, Kim KM (2002) Variations of the East Asian jet stream and Asian-Pacific-American winter climate anomalies. J Climate 15(3):306-325

Yang Song, Lau KM, Kim KM Wintertime East Asian jet stream and its association with the Asian-Pacific-American climate http://ntrs.nasa.gov/archive/nasa/casi.ntrs.nasa.gov/ 20000053089_2000036046.pdf 